\title{
Abundance of Montane Salamanders Over an Elevational Gradient
}

\author{
Daniel Hocking ${ }^{1}$, John Crawford ${ }^{2}$, William Peterman ${ }^{3}$, and Joseph Milanovich ${ }^{4}$ \\ ${ }^{1}$ Frostburg State University \\ ${ }^{2}$ National Great Rivers Research and Education Center \\ ${ }^{3}$ The Ohio State University \\ ${ }^{4}$ Loyola University Chicago
}

July 7,2020

\begin{abstract}
Climate change is expected to systematically alter the distribution and poEurycea pulation dynamics of species around the world. The effects are expected to be particularly strong at high latitudes and elevations, and for ectothermic species with small ranges and limited movement potential, such as salamanders in the southern Appalachian Mountains. In this study, we sought to establish baseline abundance estimates for plethodontid salamanders (family: Plethodontidae) over an elevational gradient in Great Smoky Mountains National Park. In addition to generating these baseline data for multiple species, we describe methods for surveying salamanders that allow for meaningful comparisons over time by separating observation and ecological processes generating the data. We found that Plethodon jordani had a mid-elevation peak (1500 $\mathrm{m})$ in abundance and Desmognathus wrighti increased in abundance with elevation up to the highest areas of the park (2025 m), whereas Eurycea wilderae increased in abundance up to $1600 \mathrm{~m}$ and then plateaued with increasing uncertainty. In addition to elevation, litter depth, herbaceous ground cover, and proximity to stream were important predictors of abundance (dependent upon species), whereas daily temperature, precipitation, ground cover, and humidity influenced detection rates. Our data provide some of the first minimally biased information for future studies to assess changes in the abundance and distribution of salamanders in this region. Understanding abundance patterns along with detailed baseline distributions will be critical for comparisons with future surveys to understand the population and community-level effects of climate change on montane salamanders.
\end{abstract}

\section{Hosted file}

Hocking_et_al_SalamanderAbundance_Final.docx available at https://authorea.com/users/340410/ articles/467744-abundance-of-montane-salamanders-over-an-elevational-gradient

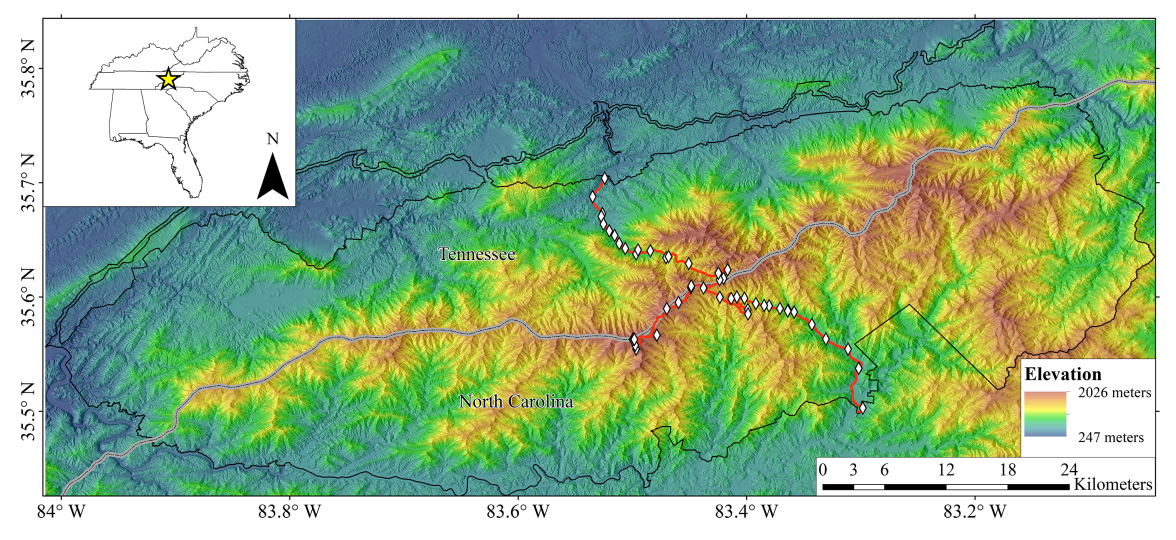



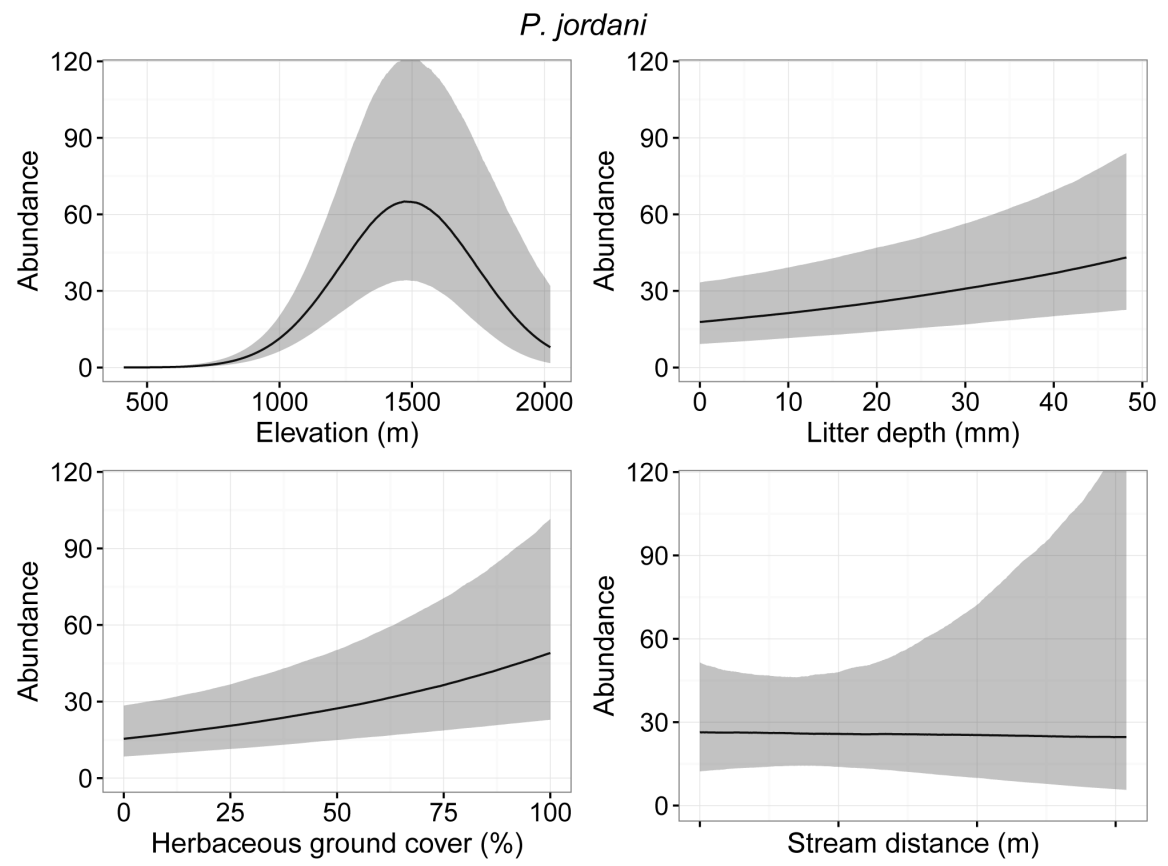

D. wrighti
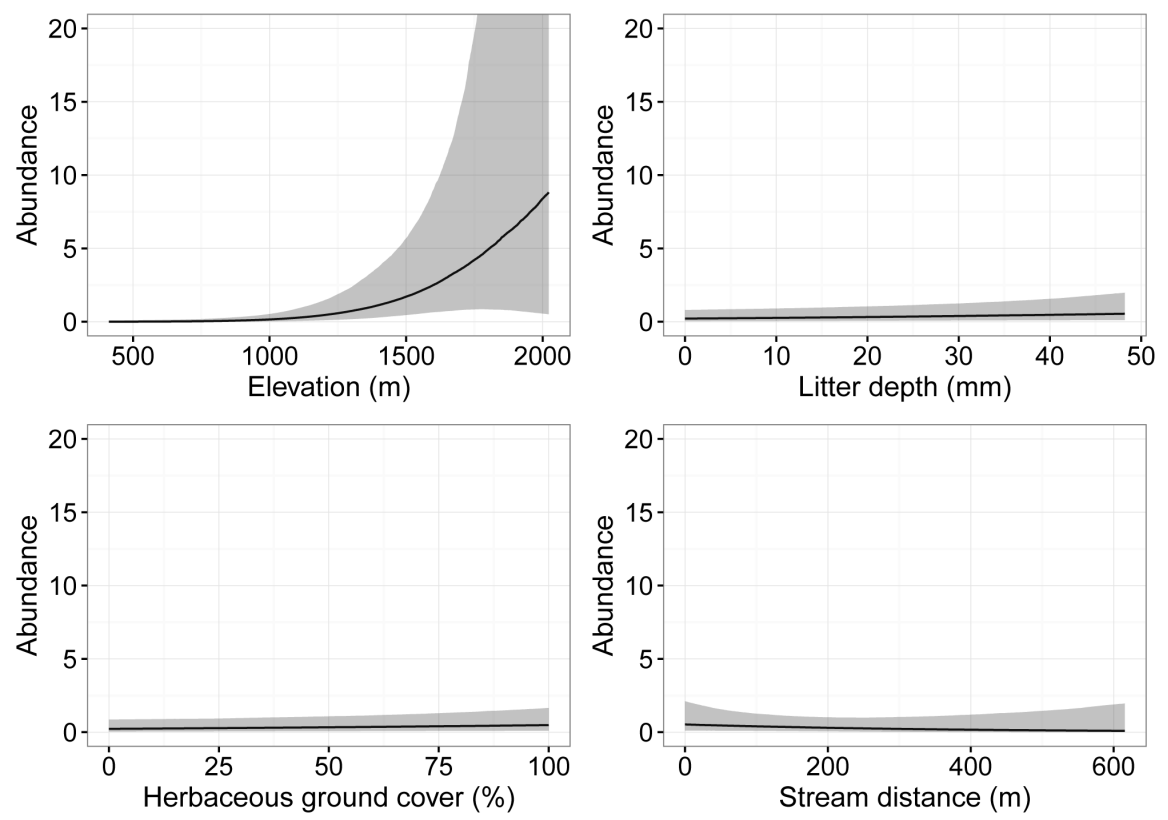

E. wilderae
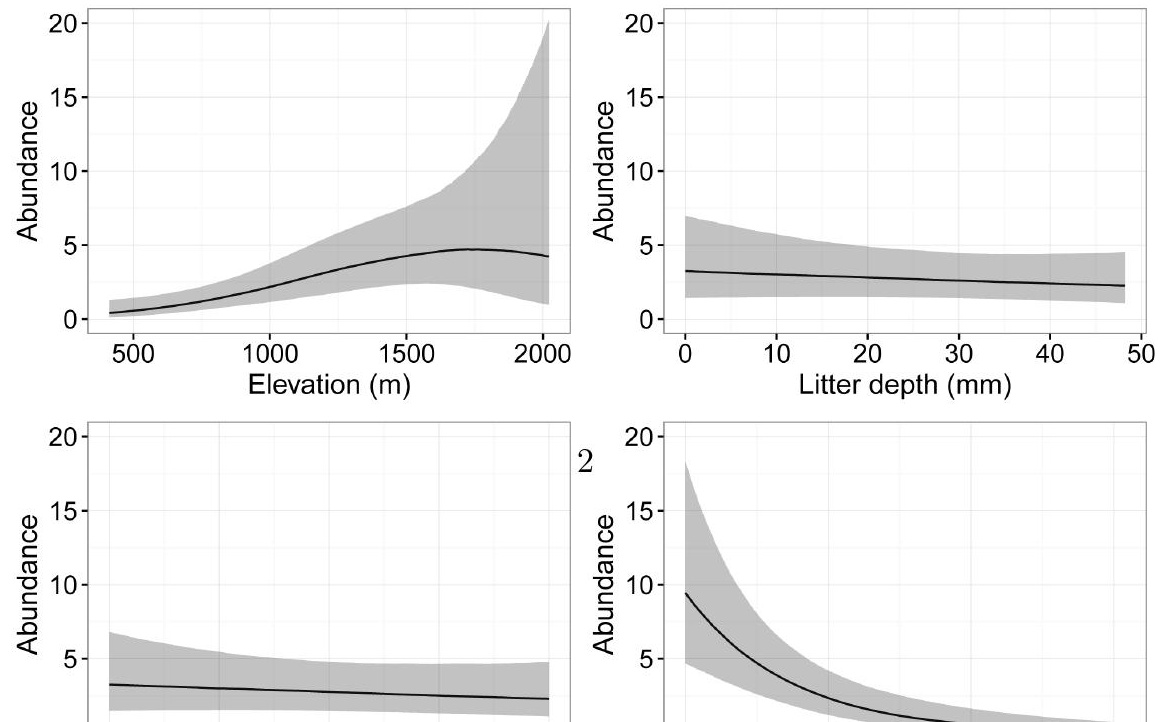
P. jordani
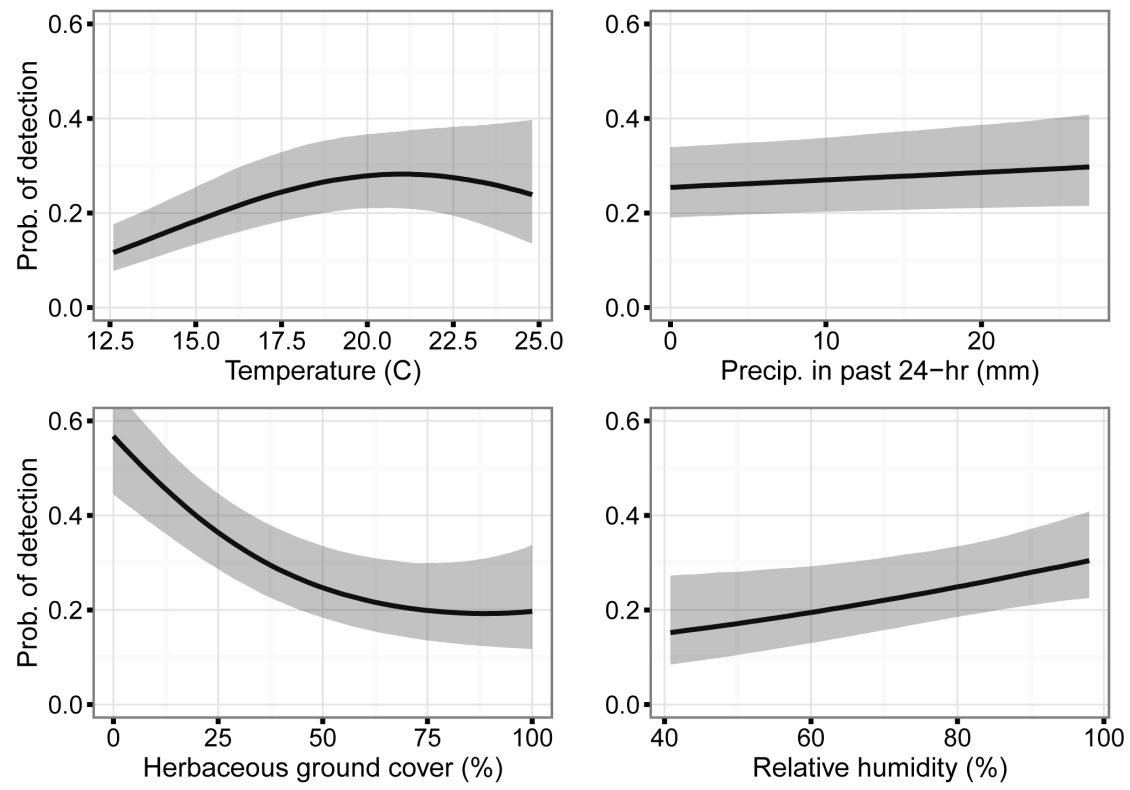

D. wrighti
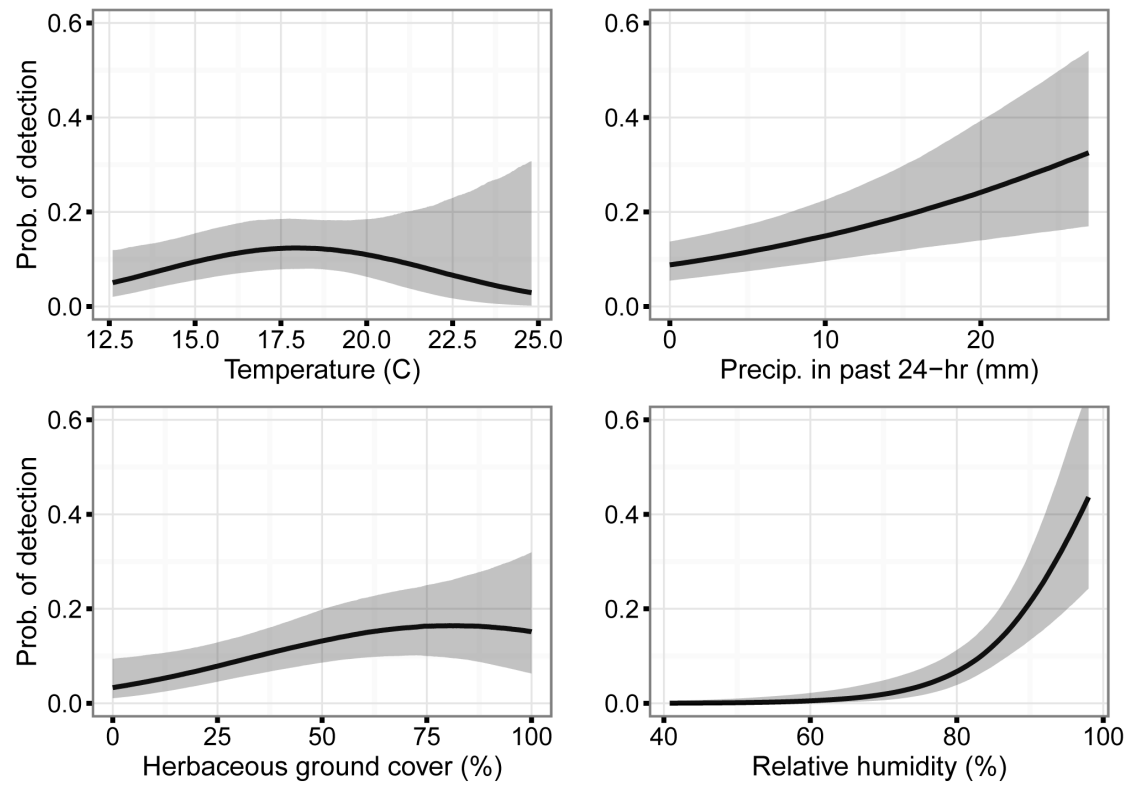

E. wilderae
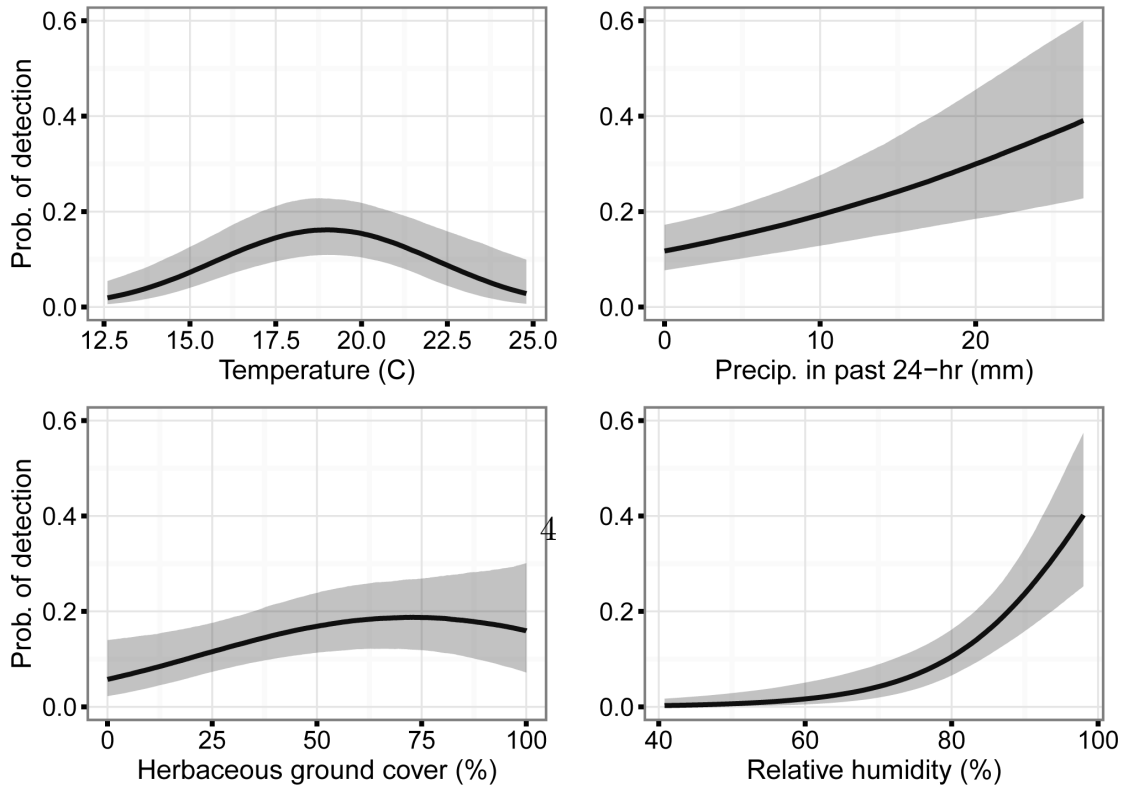


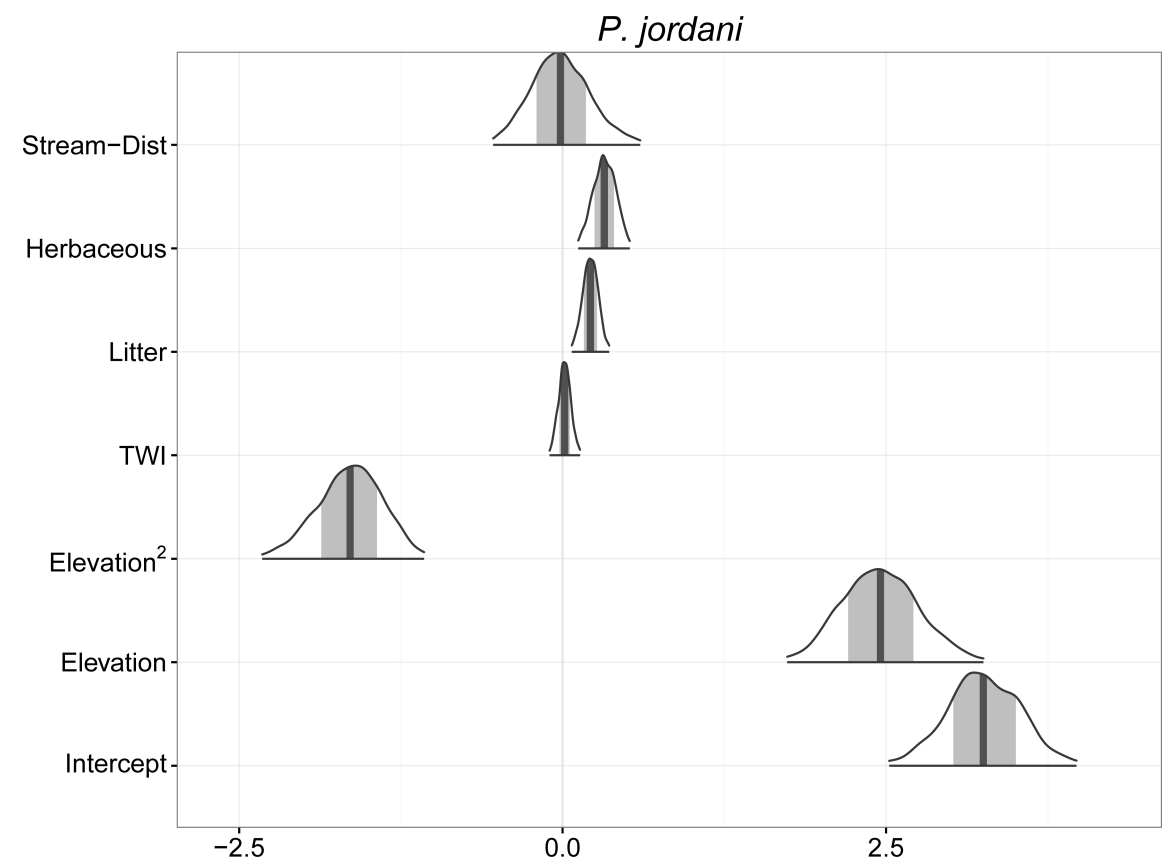




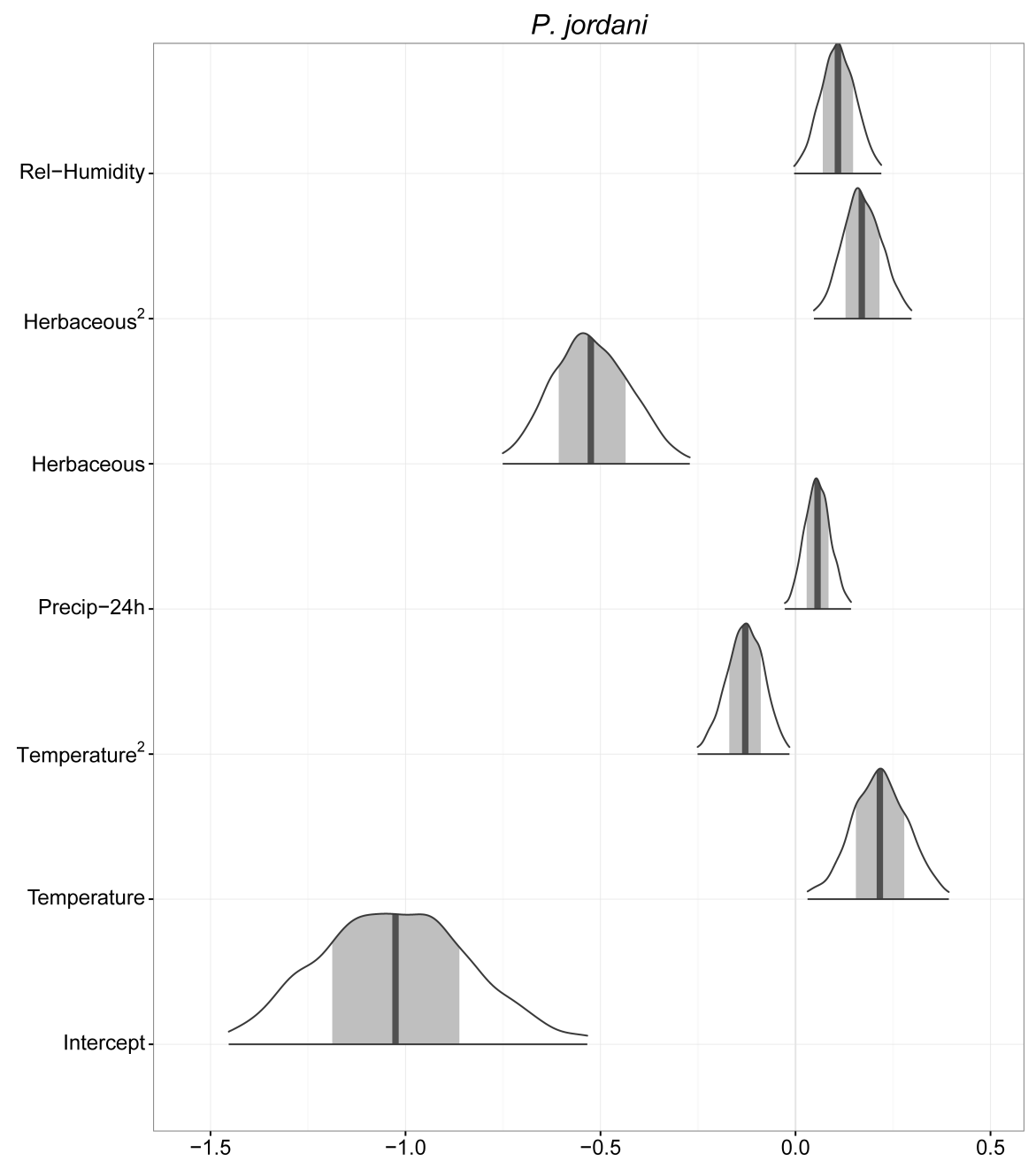

